\title{
Significado do judô paralímpico: um estudo de caso
}

\section{Significado del, judo paralímpico: un estudio de caso}

\section{The meaning of the paralympic judo: a case study}

\author{
Cardoso, A. ${ }^{1}$ Zanetti, M. ${ }^{1,2}$, Correa M. ${ }^{1}$, Sermarini, M. ${ }^{1,}$ Freire, E. ${ }^{1}$, Rodrigues, G. ${ }^{1}$, Brandão, MRF ${ }^{1}$ \\ ${ }^{1}$ Universidade São Judas Tadeu; ${ }^{2}$ UNIP São José do Rio Pardo
}

\begin{abstract}
RESUMO
Na busca pela compreensão do significado do judô paralímpico e do impacto desta modalidade na vida do atleta, foi desenvolvido um estudo de caso, de natureza qualitativa, com a participação de um atleta paralímpico da seleção brasileira de judô, que obteve resultados importantes no cenário internacional. A Abordagem História Oral de Vida fundamentou a realização da entrevista, salientou o fenômeno da vida do atleta e privilegiou uma visão contextualizada da situação e dos processos de interação deste atleta com descrição de eventos de sua vida antes e durante a trajetória esportiva, e a expressão de sua luta e estratégias de superação das adversidades. Também foi possível conhecer a trajetória esportiva, o processo de aceitação da deficiência e a aderência ao esporte adaptado. O esporte significou a possibilidade de exercer sua autonomia e, ao mesmo tempo, desempenhar seu papel social e representou o espaço para mostrar sua competência e obter reconhecimento social, a partir do bom desempenho obtido e das vitórias. Assim, pode-se concluir que a ocorrência de um determinado fenômeno (no caso a cegueira) foi ao mesmo tempo um produto e um produtor da mudança evolutiva do atleta.
\end{abstract}

Palavras chave: Atleta Paralímpico; Esporte Paralímpico; Deficiência Visual; Judô; Significado.

\section{RESUMEN}

En la búsqueda por la comprensión del significado del judo paralímpico y del impacto de esta modalidad en la vida del atleta, se desarrolló un estudio de caso, de naturaleza cualitativa, con la participación de un atleta paralímpico de la selección brasileña de judo, que obtuvo resultados importantes en el escenario internacional. El Enfoque Historia Oral de Vida fundamentó la realización de la entrevista, subrayó el fenómeno de la vida del atleta y privilegió una visión contextualizada de la situación y de los procesos de interacción de este atleta con descripción de eventos de su vida antes y durante la trayectoria deportiva, y la expresión de su lucha y estrategias de superación de las adversidades. También fue posible conocer la trayectoria deportiva, el proceso de aceptación de la discapacidad y la adherencia al deporte adaptado. El deporte significó la posibilidad de ejercer su autonomía y, al mismo tiempo, desempeñar su papel social y representó el espacio para mostrar su competencia y obtener reconocimiento social, a partir del buen desempeño obtenido y de las victorias. Así, se puede concluir que la ocurrencia de un determinado fenómeno (en el caso de la ceguera) fue al mismo tiempo un producto y un productor del cambio evolutivo del atleta. Palabras clave: Atleta Paralímpico; Deporte Paralímpico; Deficiencia visual; judo; Significado.

\section{ABSTRACT}

In the search for an understanding of the meaning of Paralympic judo and the impact of this modality on the athlete's life, a case study of a qualitative nature was developed with the participation of a Paralympic athlete of the Brazilian judo team, who obtained important results in the international scenario. The Oral History of Life Approach based the

Correspondence to: Cardoso, Ana. Dirección Postal: Universidade São

Judas Tadeu, São Paulo (Brasil) Email: nanaaluap@yahoo.com.br 


\section{Significado do judô paralímpico}

interview, emphasized the phenomenon of the athlete's life and privileged a contextualized view of the situation and the interaction processes of this athlete with a description of events of his life before and during the sporting trajectory, and the expression of their struggle and strategies to overcome adversities. It was also possible to know the sporting trajectory, the process of acceptance of the disability and the adherence to the adapted sport. The sport meant the possibility of exercising its autonomy and, at the same time, playing its social role and represented the space to show its competence and obtain social recognition, from the good performance obtained and the victories. Thus, it can be concluded that the occurrence of a certain phenomenon (in this case blindness) was at the same time a product and a producer of the evolutionary change of the athlete.

Keywords: Paralympic Athlete; Paralympic Sport; Visual impairment; Judo; Meaning.

\section{INTRODUCÃO}

As práticas esportivas adaptadas começaram a ser realizadas após a segunda guerra mundial, com o intuito de auxiliar pessoas com deficiência na reabilitação física, social e psicológica. Com essa adaptação, grande parte dos atletas com deficiência tiveram a oportunidade de vivenciar e experimentar as possibilidades do seu corpo, conhecer seus limites e capacidades e, portanto, ser um agente facilitador na mudança de atitude pessoal no que tange a própria deficiência, uma vez que, o esporte contribuía com amplas experiências e neste contexto, salientava-se não apenas a importância que possui na vida do sujeito, mas os benefícios conquistados por meio da participação esportiva (Wheeler, 1996). Atletas com deficiência agora competem de forma rotineira a nível nacional e internacional, com a participação nos Jogos Paralímpicos e campeonatos mundiais.

Os Jogos Paralímpicos são o maior evento do esporte de elite para atletas com deficiência. Teve início na década de 1960 e um aumento significativo de participantes ao longo desses anos, indo de 400 na primeira paralimpíada para mais de 5000 na Rio 2016. De acordo com alguns autores, o esporte paralímpico permite ao atleta ser reconhecido por suas potencialidades e não apenas por suas limitações, sendo capaz de atingir feitos tão importantes quanto os atletas convencionais (Wheeler., 1996; Le Clair, 2011; Purdue \& Howe, 2012b).

Nas últimas décadas, o esporte paralímpico brasileiro vem ganhando maior visibilidade e atenção. Para Marques et al. (2013), o esporte tem recebido mais recursos econômicos, com o aumento na verba destinada às instituições organizadoras e no financiamento dos atletas, além de avanços nos métodos de treinamento aplicados, que resultaram em melhores resultados dos atletas e maior divulgação por parte da mídia.

Os Jogos Paralímpicos Rio 2016, foi um acontecimento emblemático no Brasil no que se refere ao envolvimento das pessoas com deficiência na busca por atividade física esportiva, por notar o reconhecimento e a valorização dos direitos de cidadania, apesar ainda do pouco investimento nas políticas públicas dos governos nas diversas esferas (PNUD, 2017).

No entanto, o esporte paralímpico como qualquer atividade esportiva não é somente a expressão de necessidades fisiológicas, mas também de necessidades psicológicas e dos significados que orientam sua prática. Para Torregrossa \& Lee (2000) os valores são princípios ou crenças consideradas significativas ou desejáveis, eles ajudam a guiar o comportamento, definem metas e estabelecem padrões de comportamento. Em outras palavras, os valores são critérios que as pessoas usam para selecionar e justificar suas ações. Lee, Whitehead, Ntoumanis, \& Hatzigeorgiadis (2008) afirmam que se os valores humanos guiam suas ações e governam sua percepção da realidade, então eles também influenciam atitudes e comportamentos no esporte, sua direção e intensidade.

Assim, o valor ou significado atribuído ao esporte poderia explicar o envolvimento persistente com o esporte de competição, uma atividade, de eleição, que os atletas passam um tempo de sua vida em realizá-la de forma regular e na qual investem tempo e energia. Contudo, o significado é um fator que pode influenciar no tipo de interação que o atleta tem com as atividades esportivas, por evocar sentimentos, fomentando quem o atleta é, o que vem a ser na prática esportiva um fenômeno multidimensional, influenciado pelo contexto Torralba, Braz, \& Rubio, (2017). 


\section{Cardoso, A. (1), Zanetti, M. (1,2), Correa M. (1), Sermarini, M., Freire, E.(1), Rodrigues, G.(1), Brandão, M.R.F.(1)}

Sabe-se ainda que o significado de uma atividade é constituído por diversos elementos que procedem de diferentes experiências; assim, mais do que estar relacionado ao contexto, está essencialmente unido a ele (Brandão et al., 2011\& Urra, Núñez, Oses, \& Sarmiento, 2018).

A Abordagem História Oral de Vida, salienta o fenômeno da vida do atleta e possibilita um novo olhar sobre essa importante questão. Estudos sobre historia oral privilegiam uma visão contextualizada da situação e dos processos de interação deste atleta, paralímpico, com descrição de eventos de sua vida antes e durante a trajetória esportiva, e a expressão de sua luta e estratégias de superação das adversidades.

Considerando a ausência de estudos sobre o significado atribuído a uma atividade de eleição em atletas paralímpicos, o objetivo desse estudo foi compreender, na perspectiva de um judoca paralímpico com altos rendimentos esportivos, tanto o significado quanto o impacto que o esporte teve em sua vida, sua trajetória esportiva, o processo de aceitação da deficiência e a aderência ao esporte adaptado.

\section{MATERIAL E MÉTODOS}

Este estudo trata de um estudo de caso qualitativo com o objetivo de conhecer elementos da vida do atleta antes e após sua inserção no esporte paralímpico por meio da História de Vida Oral. Para atingir este objetivo, Meihy \& Holanda (2007) destacam a importância de se realizar um planejamento cuidadoso de cada etapa da pesquisa. Para os autores, é fundamental identificar a pessoa. Neste estudo, a pessoa investigada foi constituída por um atleta de judô paralímpico, portador de deficiência visual cuja classificação funcional realizada pelo Comitê Paralimpico Internacional foi de cegueira total (B1), que se refere ao atleta que não tem percepção luminosa em ambos os olhos e apresenta incapacidade de reconhecer formatos a qualquer distância ou direção.

Os estudos realizados como estudo de caso possuem algumas particularidades em relação aos procedimentos éticos, uma vez que, o sujeito pode ser identificado. Assim, as questões éticas da pesquisa foram amplamente discutidas e incorporadas a esta pesquisa respeitando-se a decisão do atleta sobre a sua participação frente à apresentação clara dos objetivos e procedimentos da mesma. Desse modo, antes de se iniciar os procedimentos da pesquisa em si, o estudo foi aprovado pelo Comitê de Ética da Universidade São Judas Tadeu de acordo com o processo número CAAE: 50150615000000089.

O participante, que doravante será denominado $\mathrm{T}$, é multimedalhista em Jogos Paralímpicos (no momento da entrevista, contava com quatro medalhas de ouro e uma medalha de bronze). Nasceu em 1970 e, desde então, reside na região metropolitana de São Paulo. Aos 13 anos, brincava junto aos amigos com estilingue quando foi atingido por uma semente de mamona, provocando um descolamento da retina esquerda que levou à perda total da visão desse olho, passando a ser monocular. Aos 19 anos, foi diagnosticado com uma infecção no olho direito, levando-o à cegueira total.

A entrevista, que teve duração de 60 minutos aproximadamente, foi realizada após o treino de $\mathrm{T}$ com a seleção brasileira de judô convencional, no Centro de Treinamento de judô no Ginásio do Ibirapuera, em São Paulo - Capital. A entrevista foi iniciada com o seguinte mote: "conte-me sua história de vida". A sequência da entrevista foi norteada com o objetivo de coletar informações demográficas e dados que auxiliassem na compreensão da trajetória da vida, processo de aceitação da deficiência, aderência ao esporte adaptado, significado atribuído a ele, as experiências enfrentadas ao longo da carreira esportiva proporcionadas pela prática do paradesporto e a participação na seleção brasileira e nos Jogos Paralímpicos, o que permitiu estabelecer uma base para o desenrolar narrativo. Os relatos envolveram sentimentos e conteúdos emocionalmente mobilizadores e a pesquisadora atentou-se a ter uma atitude empática e disponível para abordar as questões trazidas à tona.

A entrevista foi gravada e, posteriormente, transcrita para facilitar a análise da narrativa biográfica (Rubio, 2001). Assim, foi possível identificar elementos para reflexão e compreensão do significado de ser atleta de judô paralímpico, bem como os contextos que permeavam a trajetória do atleta. Procurou-se, então, realizar uma análise que possibilitasse transitar entre os pontos gerais e específicos por ele evidenciados 


\section{Significado do judô paralímpico}

com a intenção de compreender a história de vida oral narrada, pois a pratica esportiva é um processo complexo que sofre interferência do atleta, bem como pelo ambiente (treinadores, famílias, clubes) (Torregrosa, Chamorro, Ramis, 2016).

\section{O percurso de T. no judô}

O atleta foi analisado em sua totalidade, com seus sentimentos, histórias de vida, experiências, crenças, estratégias de sobrevivência e, especialmente, como um ser humano em desenvolvimento. Sua percepção, ao atribuir significado de ser um atleta paralímpico de judô pôde ser observada no seu discurso, que apresenta elementos de sua história de vida, sendo a capacidade de superação de adversidades intrinsecamente relacionada às suas crenças.

O percurso traçado por T. no esporte teve início antes de perder a visão. Foi seu pai quem o estimulou a praticar o judô, aos 7 anos e apenas dois anos depois começou a competir. A deficiência não o impediu de continuar praticando a modalidade, ao contrário, a prática esportiva contribui para que se adaptasse à sua nova condição. Ele afirma:

“... eu tinha que retomar minha vida rapidamente porque a minha vida era muito corrida e eu tinha que cumprir algumas obrigações da minha vida mesmo. Já era pai e precisei me recuperar muito rápido para poder sustentar minha família. Nem tive muito tempo de pensar na minha cegueira."

Com este discurso, T. mostrou o momento de aceitação da deficiência, ao enfatizar o aprendizado desse novo processo social por meio do esporte, que para Guaragna, Pick \& Valentini (2005) e Rechineli et al. (2008), permite desenvolver as habilidades de comunicação, proporciona oportunidades para 0 indivíduo deficiente valorizar as suas ações, reforçando as vivências positivas e a autonomia (Depauw \& Gavron, 2005).

Em seu relato, T. evidencia o importante papel de seu pai nesse momento de aceitação e no retorno à prática do judô. É notório o significado e importância que T. atribui ao modo como o pai estimula para que fosse autônomo, possibilitando que fosse "percebido" pela sociedade como um sujeito "normal" em suas atividades. Ele afirma:

\begin{abstract}
Quando eu fiquei portador de deficiência visual meu pai me manteve 3, 4 meses. Depois, vimos que não tinha mais jeito. Ele falou "Está na hora de você se virar novamente. Eu não vou te dar mais nada. Você vai ter que se virar de hoje por diante" E, realmente, se ele tivesse me dado algumas coisas, eu teria me acomodado, esperando por ele. Eu não teria o que eu tenho hoje, minha cidadania, minha dignidade, minhas coisas se não fossem as palavras dele: "De hoje em diante, vai trabalhar e viver do seu suor". (T.)
\end{abstract}

Mas, ao tomar a inciativa de voltar aos treinos, $\mathrm{T}$. enfrentou duas dificuldades: a primeira envolvia a autorização médica, que fez com que ele ficasse longe dos treinos por aproximadamente um ano; a segunda foi a dificuldade de aceitação de seu técnico, que lhe recomendava aguardar mais tempo para retornar. Relata ter percebido que seu técnico protelava sua volta, o que lhe causou certa decepção. Então, decidiu retomar os treinos por conta própria, como percebemos no trecho destacado a seguir:

\section{Peguei meu quimono e o abracei. Era uma sexta feira. Ai, perguntei para o meu sobrinho se ele poderia me levar para treinar. Ele prontamente falou que poderia me levar e eu peguei meu quimono e fui treinar. Chegando lá, eu não vi nenhuma diferença do judoca regular para um deficiente, eu não vi diferença nenhuma.}

Assim T., em seu discurso, traz à tona a dificuldade para ser aceito, mas mostra que logo percebeu que não havia diferença entre ele e o atleta convencional, atribuindo importância à prática esportiva no período de reabilitação, por caracterizar atividades em grupo, a fim de melhorar a autoestima. As atividades esportivas são percebidas pelas pessoas em suas vivências ao mesmo tempo que são influenciadas pela cultura dessas vivências e reproduzem o esporte de acordo com as características de sua sociedade e estrutura social. De acordo com Melhem (2012), é importante entender o ser atleta por meio das relações estabelecidas com os significados próprios do esporte, pois um mesmo processo desencadeia diferentes relações, visto que na infância a prática esportiva tem sua essência, vinculada às descobertas e desafios; na adolescência, ela apresenta um caráter de responsabilidade e exigências; já no alto rendimento, 


\section{Cardoso, A. (1), Zanetti, M. (1,2), Correa M. (1), Sermarini, M., Freire, E.(1), Rodrigues, G.(1), Brandão, M.R.F.(1)}

a prática esportiva e ser atleta tornam-se mais evidentes no mundo pela ascensão social.

Após retornar aos treinamentos, T. participava das competições de judô convencional. Um ano depois de seu retorno, conheceu o esporte paralímpico. Neste início, T. não poderia imaginar o êxito que iria ter a partir do momento em que aceitou dedicar-se integralmente a esta prática esportiva. Rapidamente ascendeu ao palco paralímpico em sua primeira participação de Judô para pessoas com deficiência visual. Sagrou-se campeão brasileiro dando-lhe direito de participar do processo seletivo para compor a seleção brasileira paralímpica.

Os atletas conseguem o status internacional no esporte adaptado, em geral, entre seis meses e dois anos de prática. As rotinas de treino e técnica os condicionam rápido para as exigências dos jogos nacionais, inclusive com oportunidade de ganhar medalhas. $\mathrm{Na}$ realidade, a iniciação no esporte é um processo informal, pois passa pelo processo de reabilitação. Mas o credenciamento e inclusão no esporte de alto rendimento acontece de forma rápida e pautada no conceito e atributos do professor/ técnico, valorizando a relação de confiança estabelecida entre atleta e técnico. A experiência anterior que possuía no esporte convencional fez com que $\mathrm{T}$. fosse notado como forte candidato na corrida pelas medalhas.

Significado do esporte paralímpico na narrativa biográfica

Considerando a narrativa de $T$. no esporte paralímpico, percebe-se que não existe um significado único ou comum na prática esportiva. Esta prática pode assumir múltiplos significados, dependendo das características do atleta, das particularidades do seu percurso esportivo e das experiências vividas neste contexto. As narrativas de T. a seguir expressam, claramente, estes múltiplos significados. Por exemplo, participar no judô paralímpico possibilitou que fosse uma pessoa com mais autonomia. Esta percepção pode ser identificada no trecho destacado: "Eu acho que o tatame é meu mundo, quando eu estou dentro, eu sou eu, não preciso mais da minha bengala, aqui é meu mundo, estou exercendo a minha profissão, estou exercendo aqui a vida inteira."
Para T., a prática do esporte também é percebida como uma forma de pertencimento social, permitindo que desempenhasse um papel no grupo em que se inseriu. Com esse sentimento, para o judoca, a participação nas competições também lhe permitiu representar seu país e outras pessoas com deficiência. Ele afirma: "Eu não vou representar o $T$. Eu vou representar uma nação de 193 milhões de brasileiros, onde 17 milhões são deficientes. Eu foco nos 17 milhões e tento trazer algum benefício não só para mim, mas para esse grupo."

Em seu relado, apresenta alguns exemplos sobre como compreende e tenta exercer seu papel social. Para T., a prática esportiva está carregada de significado, principalmente por promover informação e acesso aos pares. Neste sentido, a construção da narrativa fomenta a atitude pessoal e o olhar aos pares, vinculando o significado do esporte paralímpico à promoção da transformação social. Isso aparece quando destaca a condição da pessoa com deficiência e a dificuldade na acessibilidade:

\begin{abstract}
"Como é que um deficiente, um cadeirante vai esperar não sei quantas horas por um ônibus especial para pegar ele ou ele vai ter que ligar para "O Atende" para vir busca-lo, então dificulta muito a preparação no dia a dia da pessoa com deficiência no mercado de trabalho ou para prática do esporte. Nós temos que ter uma política que venha transformar tudo isso novamente em realidade, que a gente possa ter acessibilidade para a gente ser capaz também de estar brigando de igual para igual com as outras pessoas. Hoje em dia nem prédios públicos estão adaptados à acessibilidade adequada para deficientes, imagina dentro de estádios, ginásios, que não são preparados para receber essas pessoas para a prática de esporte."
\end{abstract}

Para T., sua participação nas competições também visava contribuir para o desenvolvimento do esporte adaptado e do judô paraolímpico: "Me sinto como um gigante, indo representar meu pais. Quero ajudar, mas de alguma outra forma, e quero enfatizar a importância dos clubes nesse processo de revelar 


\section{Significado do judô paralímpico}

novos talentos, são eles que formam o atleta, necessitam ser valorizados."

Essa preocupação com o esporte e seu desenvolvimento se expressou em outros momentos de sua entrevista, como no trecho destacado a seguir:

\begin{abstract}
"As brigas são para melhoria da seleção, por um treino melhor, para conquistar a mesma qualidade de treino do Olímpico. Isso é muito importante como hoje me dá o direito de treinar com os melhores, de treinar junto com a seleção brasileira, em cima do tatame. Então, a gente trabalha a todo momento para o melhor, e esses atletas também tem o melhor. Outras equipes que vem integrar a seleção paralímpica que vem dar essa assistência para eles, a gente demonstrando isso, a gente conquista cada vez mais para o judô paralímpico."
\end{abstract}

Em sua narrativa, T. argumentava sobre a importância que atribuia à competição e à obtenção de resultados expressivos, que lhe permitiram ter reconhecimento social. Ele afirma:

\begin{abstract}
"Eu sempre falo para os meninos que eu nunca saio do meu país, para não trazer resultado. Eu quero resultado porque eu vivo de judô. Eu quero estar no pódio, entre os 3. Eu quero continuar, se for possível, quero continuar sendo campeão paralímpico."
\end{abstract}

Talvez esteja aqui um dos sentidos da competição e do próprio ser atleta, passa-se a precisar do rendimento ao invés de somente desejá-lo, como o ser-no-mundocomo-atleta, que estabelece com o rendimento uma ligação em que este significa a própria realização do projeto: o vencer irá anunciar e posicionar sua pertinência, sua continuidade e seu sucesso, pois o mesmo será consolidado ao desenvolver as habilidades haja visto, que um atleta deve ser capaz de adaptar seu foco, a fim de superar as demandas múltiplas e em constante mudança que ele enfrenta, particularmente enquanto luta (Silva, Dias, Corte Real, \& Fonseca, 2018).

Um esportista vive através de um modo muito próprio em busca de ser mais e melhor, não só no terreno competitivo, mas também no palco social (Sérgio, 2012). Portanto, o esporte paralímpico significa também capacitação, realização pessoal, reconhecimento e superação pessoal e social do atleta (Hutzler \& Bergman 2011; Peers 2012; Purdue \& Howe, 2012a).

O processo de tornar-se atleta pode ser compatível com o processo de desenvolvimento humano, na medida em que favorece o protagonismo, autoconhecimento, busca da superação, potencializa a expressão pessoal e as relações interpessoais, dentre outras possibilidades, para construção de significado por meio da prática esportiva. (PNUD, 2017)

Em 2000 indo para Sidney conseguindo mais uma medalha de ouro, minha vida começou a melhorar como atleta de alto rendimento. E as medalhas de ouro foram conquistadas em 1996, 2000, 2004, 2008 foram conseguidas por mim.

No discurso apresentado por T., ficou evidente o esforço exercido quanto à dedicação e constante busca pela excelência e a indignação com os baixos investimentos/ recursos no paradesporto. O esporte se tornou associado à sua profissão, o valor atribuído por integrar o projeto paralímpico representava um momento significativo ao atleta. Mas, por outro lado, o foco no resultado também trazia a preocupação com seu desempenho futuro, também evidenciada em sua narrativa:

“Até quando eu posso trazer resultado para o Brasil, porque lutar eu posso lutar até 50 anos, agora até quando eu vou lá para fora e vou trazer resultados para o Brasil? aí eu não sei. Eu tenho que representar meu país, em algum lugar que eu possa trazer resultado não só para o meu país, mas para mim também, para o meu dia-a-dia, para minha vida."

Ressaltava as dificuldades enfrentadas em sua carreira esportiva, como a luta para obter patrocínios:

"De maneira ilógica a medalha de ouro não me trouxe beneficios, por precisar treinar cada vez mais para manter um nível de competição alto. Não bastasse isso, perdi meus patrocínios, porque o ciclo do paradesporto é perverso, as pessoas só querem saber de aparecer nas vésperas dos Jogos Paralímpicos. Tive então que voltar a dar aula de judô para sobreviver, foi um 


\section{Cardoso, A. (1), Zanetti, M. (1,2), Correa M. (1), Sermarini, M., Freire, E.(1), Rodrigues, G.(1), Brandão, M.R.F.(1)}

\begin{abstract}
perído muito dificil para mim. Descobri que o esporte funciona da seguinte maneira: você pode estar no auge e no minuto seguinte, no chão.”
\end{abstract}

"Consegui me manter no pódio, quase vinte anos depois da primeira medalha, mas nossos dirigentes não enxergam isso, voltei de Londres e novamente passei por dificuldades financeiras. Perdi patrocínios, as pessoas parecem não dar valor a conquistas que não sejam um ouro. O Brasil é o único lugar que não valoriza uma medalha paralímpica como deveria e nem os resultados conquistados em outras competições internacionais. Ganho hoje metade do salário que ganhava em 2003. Conto com o patrocínio do meu time e da Caixa Econômica Federal, e continuo recebendo o bolsa-atleta, mas tenho que dar palestras para me manter e à minha família. $\mathrm{Na}$ verdade, o que existe é uma grande indefinição com relação ao futuro, não sei o que esperar."

$\mathrm{O}$ esporte paralímpico de alto-rendimento no Brasil convive com carências e não tem uma estrutura organizada para sustentar sua prática, fato esse que pôde ser observado no depoimento de T., pois resultados expressivos tendem a ser fruto de ações isoladas de clubes e outras entidades, e não de programas e políticas públicas articuladas. (PNUD, 2017)

\section{DISCUSSÃO}

O esporte vem conciliando aspectos da vida dos indivíduos, que se potencializam mutuamente, ressaltando valores característicos do esporte de forma positiva (Beregüí \&, Rosendo, 2007) tais como cooperação, trabalho em equipe, disciplina ou tolerância, ao buscar a realização do homem que carrega em si, a necessidade de se emocionar, superar, jogar, brincar e comunicar (Bento, 2013).

Para Haines (1989), dificilmente encontraremos uma única definição de significado para o esporte, pois os motivos que contribuem para as pessoas permanecerem na prática esportiva, são fatores particulares e as razões da participação podem ser diversas. Já para Hutzler (2011), o significado atribuído parte da consciência, ou seja, o ato de significar é intencional.

O significado só é possível a partir da percepção humana que é inexoravelmente corporal, o que vem a ser totalmente compreensível nas contribuições de Merleau-Ponty (2006), pois a cultura é um contexto onde os homens se movimentam dando significado ao mundo vivido. Ela reside justamente nas relações humanas e na significação de suas práticas, ela é social, portanto pública.

Trata-se de um fenômeno que exerce transmissão e renovação cultural, pois deriva das características de seus praticantes e o esporte transmite valores e, por isso, interfere na formação humana ao demonstrar a capacidade de fazer uma nova vida, novos significados após o trauma/lesão, experimentar crescimento psicológico, físico e social (Day, 2013).

É fato que no esporte de elite encontrarmos as mais significativas histórias de vida, uma vez que atletas expressam episódios únicos e relevantes, distinguemse pelas fortes emoções e sentimentos provocados por diferentes motivos, conferindo a sua prática um sentido único (Costa, 2006).

Nestas situações particulares, a prática esportiva de alto rendimento permite ao atleta assegurar a sua independência financeira e transpor as consequências negativas da deficiência, além de permear no corredor do imaginário esportivo também observado no estudo de Garci e Mandich (2005). A liberdade funcional e financeira conquistada refletem-se de modo evidente na vida do atleta, explicitado no discurso de T., ao potencializar a importância da exclusividade ao esporte, por meio da emancipação financeira.

$O$ esporte incutiu no entrevistado valores da perseverança, da dedicação, da valentia, da coragem, do rigor e disciplina, entre muitos outros. Valores que são essenciais na luta do esporte, mas também na aceitação da sua deficiência. É neste contexto que olhar para a deficiência, sem a valorização das limitações, transitando da incapacidade para uma perspectiva de possibilidades no esporte e na vida (Smith \& Sparkes, 2004). 


\section{Significado do judô paralímpico}

A experiência esportiva adquirida até à data da entrevista transformou-o como atleta, mas, fundamentalmente, como ser humano, o significado atribuído ao judô mostra que a atividade se converte em paixão e aparentemente, em adaptações positivas às diferentes situações enfrentadas. Para alguns, o esporte, enquanto espaço privilegiado de crescimento e de aprendizagem pessoal é responsável pelo que são hoje como pessoas: verdadeiros seres íntegros. Dessa forma, tais elementos contribuem para reflexão e compreensão do significado de ser atleta de judô paralímpico.

O conteúdo das histórias de vida mostrou que as respostas representaram a maneira pela qual o atleta lidou com as diferentes situações vivenciadas e, assim, não há como julgar se uma resposta foi adequada ou não, pois foi a resposta que pôde produzir naquele momento. No entanto, pode-se concluir que a ocorrência de um determinado fenômeno (no caso a cegueira) foi ao mesmo tempo um produto e um produtor da mudança evolutiva do atleta.

A discussão sobre o significado do esporte para o atleta paralímpico deficiente visual da modalidade de judô é uma área nova. As dificuldades marcam a prática esportiva adaptada no país, principalmente no que tange a fomentação do esporte não mais apenas como processo de reabilitação, mas no modo competitivo. Assim, potencializado o que está historicamente posto: a prática esportiva adaptada não é vista como uma prática competitiva, o que impede uma disseminação e popularização da prática pelos pares, frequentemente cobrada no discurso de $\mathrm{T}$.

Por isso, o significado atribuído ao esporte aparece de forma singular na relação atleta-esporte que norteia a condição de lugar para viver, ser, sentir e significar a prática esportiva, pois o indivíduo em questão vincula os sentimentos à memória, aos momentos e aos eventos importantes que vivenciou. Desta forma, o espaço físico e social é culturalmente estruturado pelos sujeitos, por vivenciar as emoções que permanecem vivas na memória coletiva e adquirem um significado que transcende o sujeito no que tange a identificação com a torcida, a valorização da moral e ética, o representar a nação, a luta incessante pela vitória, o pertencer a um importante clube, conquistar títulos e obter um posto de trabalho muito almejado, porque proporciona reconhecimento e a aprovação.
Sentimentos esses importantes que influenciam na construção de significado da prática esportiva.

Em suma, a narrativa biográfica ofereceu consistente base à reflexão sobre a importância do cultivo de atividades para além do esporte. Mostraram também que o significado atribuído em ser atleta não foi o único fator determinante para permanência no esporte, mas uma dentre as diversas forças que constituíam representações sociais sobre o esporte e seu protagonista. Ao mostrar-se individualmente capaz, demonstrar combatividade na construção de sua carreira esportiva, vencendo obstáculos, como a falta de recursos ou a diferença de prêmios. Procura-se o significado de ser atleta quando se relaciona a escolha e o sentido como fenômeno que se engendram formando aquilo que mantém e direciona o atleta a sua história, haja visto que a construção de significado está atrelada à vivência e é única para cada sujeito.

No universo esportivo, o desporto para pessoas com deficiência é ímpar e distingue-se pelas suas particularidades, na sua maioria, relacionadas com as próprias potencialidades e limitações do atleta para competir principalmente quanto a locomoção.

No território brasileiro, os atletas paralímpicos alcançam visibilidade apenas nos anos em que se realizam os Jogos Paralímpicos. Nessa altura, antes, durante e após a competição - os seus nomes são revelados, os seus resultados noticiados e a sua imagem surge em vários meios de comunicação social. Para o atleta brasileiro que se inicia na competição, o esporte adaptado é gradativamente mais difícil, perante um contexto internacional onde se observa um crescente investimento.

A ausência de recursos financeiros interfere efetivamente na prática do paradesporto, pois se cria uma dependência para realizar toda e qualquer tarefa, notamos este discurso na narrativa de T. Desse modo, mas não apenas por isso, esbarramos no incentivo, no apoio e na criação de condições. Estes são aspectos fundamentais para o desenvolvimento da carreira paralímpica. Sem este auxílio, poucos serão aqueles que, individualmente, conseguirão fazer $o$ investimento necessário para alcançar lugar de destaque no esporte de elite para pessoas com deficiência. 


\section{Cardoso, A. (1), Zanetti, M. (1,2), Correa M. (1), Sermarini, M., Freire, E.(1), Rodrigues, G.(1), Brandão, M.R.F.(1)}

Impressiona a importância atribuída pelo próprio atleta quanto a divulgação e popularização da prática do paradesporto em alto rendimento, cenário este apenas explorado próximo ao maior evento paralímpico mundial esquecendo de toda preparação que antecede. Para T., destacam-se momentos que parecem revestir-se de maior significado, tais como: a participação na primeira competição internacional e paralímpica; a conquista da primeira medalha; a obtenção da primeira medalha de ouro; o instante em que se quebra o recorde; o momento em que se vence uma prova consagrando-se no pódio por 20 anos consecutivos, pós lesão ou após uma fase marcada por maus resultados desportivos; a experiência de vencer numa prova em que o atleta não era favorito; subir ao pódio e ouvir o hino nacional.

O atleta paralímpico é incitado pela conquista pessoal, pela transcendência humana e pelo reconhecimento social resultados de uma carreira desportiva meritória. Enquanto ser humano, o atleta é um projeto aberto, um ser em potencial permanente e um homem que anseia o inatingível. Ninguém nasce campeão, um atleta de elite "faz-se"! Ser esportista é contemplar o mais além, é vislumbrar o aprimoramento constante e viver em busca de consecutivos. Sonhos sempre mais altos e grandiosos.

Em termos práticos, esse estudo nos mostrou os processos de desenvolvimento envolvidos na vida do sujeito e diferentes fatores que o tornaram mais ou menos positivo, mas possibilitou reconhecer, de forma clara, a potencialidade humana para superar as dificuldades impostas pelo viver e o esporte como um potencial produtor dessa superação. Vale ressaltar que esse estudo se limitou a entrevistar um atleta paralímpico por meio de sua história oral de vida, portanto, seus dados não podem ser generalizados.

\section{REFERÊNCIAS (APA 6 ${ }^{\mathrm{a}}$ EDICION)}

1. Bento, J. (2013). Dos Sentidos do Agonismo Grego e do Desporto.

2. Beregüí G. \& Rosendo; G. de los F. R. E. J.(2007) Valores En El Deporte Escolar: Estudio Con Profesores De Educación Física Cuadernos de Psicología del Deporte, vol. 7, núm. 2, p. 89-103
3. Brandão, M. R. F. Serpa, S., Ruy,K., Duarte A., \& Alfonso A. M., (2011).El significado del arbitrar: percepción de jueces de fútbol profesional. Revista de Psicología del Deporte, Palma, v. 20, n. 2, p. 275-286. https://doi.org/10.5093/rpadef2018a6

4. Costa, A. S. (2006) Desporto e Antropologia. In: Pereira, A. L., Costa, A., \& Garcia, R. P. (2006). O desporto entre lugares: O lugar das ciências humanas para a compreensão do desporto. Porto: Universidade do Porto, 3772. https://doi.org/10.5628/rpcd.01.01.80

5. Day, M. C. (2013). The role of initial physical activity experiences in promoting posttraumatic growth in Paralympic athletes with an acquired disability. Disability and rehabilitation, 35(24), 2064-2072. https://doi.org/10.3109/09638288.2013.8058 22

6. Depauw, K., y Gavron, S. (2005). Disability Sport (2 ed.). Champaign: Human Kinetics.

7. En Nascimento, J. V, Bogndan, R. y Biklen, S. (1994). Investigação qualitativa em Educação. Porto: Porto Editora

8. Ferreira, N. S. (2014) A transição de carreira dos bicampeões mundiais de basquetebol: uma análise em narrativas biográficas. [123f]. Dissertação (Mestrado) - Escola de Educação Física e Esporte, Universidade de São Paulo, São Paulo. https://doi.org/10.11606/d.39.2014.tde20022015-093152

9. Garci, T. H., \& Mandich, A. (2005). Going for Gold: Understanding occupational engagement in elite- level wheelchair basketball athletes. Journal of occupational science, $\quad 12(3), \quad 170-175$. https://doi.org/10.1080/14427591.2005.9686 560

10. Haines, C. (1989). Coaching Certification Manual: Level 2 Women. Gymnastics Canada Gymnastique, Ontario, Canadá.

11. Hutzler, Y., \& Bergman, U. (2011). Facilitators and barriers to participation while 


\section{Significado do judô paralímpico}

pursuing an athletic career. Therapeutic Recreation Journal, 45(1), 1-16.

12. Le Clair, J. (2011) Transformed identity: from disabled person to global Paralympian. Sport in Society. 14(9), 1116-1130. https://doi.org/10.1080/17430437.2011.6147 68

13. Lee, M. J., Whitehead, J., Ntoumanis, N., \& Hatzigeorgiadis, A. (2008). Relationships among values, achievement orientations, and attitudes in youth sport. Journal of sport and exercise psychology, 30(5), 588-610. https://doi.org/10.1123/jsep.30.5.588

14. Meihy, J. C. S., B., \& Holanda, F. (2007). História oral: como fazer, como pensar. São Paulo: Contexto.

15. Melhem, T. X. (2012). O processo de formação de atletas competitivos sob a perspectiva fenomenológico existencial. 2012.104f. Dissertação (Mestrado) - Escola de Educação Física e Esporte, Universidade de São Paulo, São Paulo, 2012. https://doi.org/10.11606/d.39.2012.tde02052012-082446

16. Merleau-Ponty, M. M. (2006). Fenomenologia da Percepção. São Paulo: Martins Fontes.

17. Peers, D. (2012). Patients, athletes, freaks: Paralympism and the reproduction of disability. Journal of Sport and Social Issues, 36(3), 295-316. https://doi.org/10.1177/0193723512442201

18. PNDU, (2017). Relatório de Desenvolvimento Humano Nacional Movimento é Vida: Atividades Físicas e Esportivas para Todas as Pessoas. - Brasília:. 392 p.: il., gráfs.

19. Purdue, D. E. J., \& Howe, P. D. (2012). See the sport, not the disability: exploring the Paralympic paradox. Qualitative research in sport, exercise and health, 4(2), 189-205. https://doi.org/10.1080/2159676x.2012.6851 02

20. Purdue, D. E., \& Howe, P. D. (2012a). Empower, inspire, achieve:(dis) empowerment and the Paralympic Games. Disability \& Society, 27(7), 903-916. https://doi.org/10.1080/09687599.2012.6955 76

21. Ramos, V., \& Tavares, F. (Orgs.) Jogos desportivos: formação e investigação. Florianópolis: UDESC.

22. Rechineli, A., Porto, E. T. R., \& Moreira, W. W. (2008). Corpos deficientes, eficientes e diferentes: uma visão a partir da Educação Física. Revista Brasileira de Educação Especial, 14(2), 293-310. https://doi.org/10.1590/s141365382008000200010

23. Rubio, K. (2001). O Atleta e o Mito do Herói. São Paulo: Casa do Psicólogo.

24. Sérgio, M. (2012). Crítica da Razão Desportiva. Lisboa: Instituto Piaget.

25. Silva, V., Dias, C., Corte - Real, N., \& Fonseca, A. (2018). Mental toughness in Judo: perceptions of athletes. Cuadernos de Psicología del Deporte, Vol 18(3), 86 - 101

26. Smith, B., \& Sparkes, A. (2004). Men, sport, and spinal cord injury: An analysis of metaphors and narrative types. Disability \& Society, 19(6), 613-626. https://doi.org/10.1080/09687590420002525 33

27. Torralba, M.A., Braz, M.V. \& Rubio, M.J. (2017). Motivos para la práctica deportiva de atletas paralímpicos españoles. Revista de Psicología del Deporte, 26 (1), 49-60.

28. Torregrosa, M., Chamorro, J. y Ramis, Y. (2016). Transición de junior a senior $\mathrm{y}$ promoción de carreras duales en el deporte: una revisión interpretativa. Revista de Psicología Aplicada al Deporte y al Ejercicio Físico,1,e6.https://doi.org/10.5093/rpadef201 $6 \mathrm{a} 6$

29. Torregrossa, M., \& Lee, M. (2000). El estudio de los valores en psicología del deporte. Revista Psicología del Deporte, 9(1), 71-83. ttps://doi.org/10.5093/rpadef2018a6

30. Urra, B.; Núñez, C.; Oses, J. y Sarmiento, G. (2018) "Variables psicológicas influyentes en el desempeño de árbitros FIFA". Revista de 
Cardoso, A. (1), Zanetti, M. (1,2), Correa M. (1), Sermarini, M., Freire, E.(1), Rodrigues, G.(1), Brandão, M.R.F.(1)

Psicología Aplicada al Deporte y al Ejercicio

Físico Vol. $3 \quad$ (2), 1-11

https://doi.org/10.5093/rpadef2018a13

31. Wheeler, G. D., Steadward, R. D., Legg, D., Hutzler, Y., Campbell, E., \& Johnson, A. (1999). Personal investment in disability sport careers: An international study. Adapted Physical Activity Quarterly, 16(3), 219-237. https://doi.org/10.1123/apaq.16.3.219 